\title{
DIVERSIFIED EXPRESSIONS OF ARCHITECTURAL FORMS - SEARCHING THE LAWS OF SPACE COMPOSITION AND GROWTH FROM THE RIVER NETWORK
}

\author{
${ }^{1}$ Xue KANG ${ }^{*}{ }^{2}$ Gabriella MEDVEGY \\ ${ }^{1}$ Marcel Breuer Doctoral School, Faculty of Engineering and Information Technology \\ University of Pécs, Boszorkány u. 2, H-7624 Pécs, Hungary, e-mail: 250659063@qq.com \\ ${ }^{2}$ Department of Interior, Applied and Creative Design, Institute of Architecture \\ Faculty of Engineering and Information Technology, University of Pécs, Boszorkány u. 2 \\ H-7624 Pécs, Hungary, e-mail: medvegygabriella@mik.pte.hu
}

Received 23 October 2018; accepted 4 April 2019

\begin{abstract}
Human beings live in a complex and magical system of nature. The constitution of everything is like the structure science of architecture, which presents various forms and combinations. The development of structure science makes modern architecture show the high unity of internal structure and external contour. Through the study of branch networks formed by rivers, the mystery of branch growth can be found, for instance fractal self-similarity, preferential growth at the tops, avoidance of homogeneity, etc. Based on the understanding of branch ecosystem, everyone can try to build a sustainable surface structure by mimicking the laws of river network.
\end{abstract}

Keywords: River network, Branch, Growth structure, Architectural form

\section{Exordium}

The laws of nature are often hidden reflection of social and economic development and solutions, which of course includes architecture [1]. If they do not present a general state, then it is very likely that there is a reason or purpose for them to do so [2]. Many excellent architects and structural engineers have learned new laws of space growth from disciplines such as physics and natural science.

Just as the expression of architectural forms is rarely singular or homogenized, a new spatial expression can be created if the complex geometry and spatial variables can be synthesized, transformed, deformed and hybridized by using the formal system.

\footnotetext{
${ }^{*}$ Corresponding Author
} 


\section{Orderly pattern - river network}

A river network can be understood as a linear natural waterway in which rivers often or intermittently flow on the surface of a land. The formation of river network system is also the formation of the path and pattern of water erosion on the surface.

\subsection{Morphology of river network}

River network morphology refers to the combined form of every main stream and tributary in the river network [3]. Because of the complex and changeable geological and geographical conditions, the river network in different regions has different plane morphology. According to the different topological structure of the river network, the shape of river network can be divided into feather, leave and branch (Fig. 1) [4]. Feather shape is a large number of short tributaries that run vertically into the main stream, like a feather. Leave is where it can distinguish the trunk of the veins and its subordinate parallel branches. Branch is when the river network distribution similar to branches. Overall, the structure of branched river networks remains relatively stable in different river network morphology.

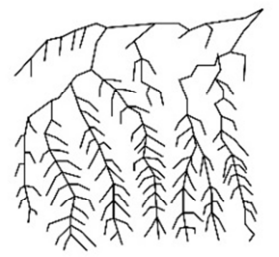

Fcather (River network)

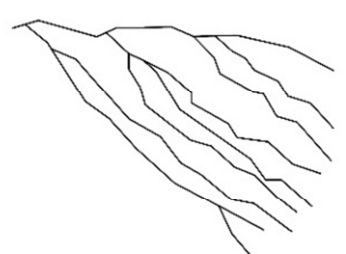

Leave (River network)

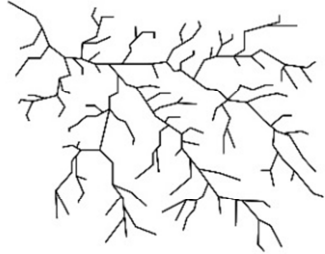

Branch (River network)

Fig. 1. Typical river network morphology

\subsection{Research methods of river network morphology}

Horton [5] and Strahler [6] developed a Horton-Strahler system to classify, rank and sort natural waterways in watersheds. The Horton's law based on it is regarded by most researchers as the principle of river network research [7]. The Horton-Strahler classification method uses branch ratio, river length ratio and area ratio to describe the river network quantitatively. It characterizes the river network in a statistical sense. A large number of research results show that most natural river networks have linear laws similar to those reflected by Horton's law.

But some researchers believe that Horton's law reflects the 'most likely state' in random river networks. The same phenomenon exists because of many artificial river networks based on random theory. For example the limited layout random drainage system model of Shreve [8] and the random chain length model proposed by Smart [9]. Since fractal geometry emerged in the 1970's, Horton's law and fractal thought have gradually merged. The application of the branch concept in fractal theory to the study of river network morphology brings the change trend in the nature of river network growth system. 


\section{Characteristics of river network growth}

As in the process of building architectural design, geographical location, surrounding environment and architectural orientation, and many other factors have an impact on the development of design [10]. The formation of patterns of waterway on the surface is also related to various environmental factors, the surface contour, the permeability of soil, the type of rock, the state of vegetation cover, etc.

\subsection{Self-similarity}

Morphology of river network shows regular arrangement in plane and has certain similarity in different scales. Self-similarity is a scale-invariance, that is, if you look at fractals at different scales, you will see approximately the same image. If you zoom in on the entire object and then zoom in on the local part, you can see similar structural features. Morphology of any type of river network, including parallel, dendrite, radiate and grillage has the self-similarity of fractal geometry. It can also be said that this is the most fundamental and remarkable feature of the branch in fractal geometry.

But this self-similarity is less strict, allowing partial dissimilarity in the overall similarity because it does not need to be and cannot be exactly the same. For example, the Koch curves. The self-similarity of the river network branch means that the parts are as complex as the whole: the same twists and turns, trivial, messy, irregular, and not smooth. Most natural systems are globally deterministic and locally random. A healthy and mature evolutionary system allows for random error.

\subsection{Preferential growth at the tips}

The growth of the river network is like any other random branch: randomness is ubiquitous, but biased by preferential growth at the tips. Apical dominance is most pronounced in plant fractals. But the formation of river branches is consistent with the principle of energy transport in plant leaf veins: The tip of the branch is the direction in which the most kinetic energy is concentrated, that is, the most growing part.

In plant branches, the tip inhibits the growth of lateral buds, and the strength decreases with increasing distance. The same applies to branches of river networks. The upper reaches of the river network have greater kinetic energy due to the large amount of water, and the preferential growth of branches at the tips is the most obvious. With the recursion of the river branches, to the lower reaches of the river, the amount of water decreased, the kinetic energy weakened, preferential growth at the tips trend gradually weakened.

\subsection{Self-avoiding}

River networks tend to be self-avoiding: stream-heads hardly ever cut back across other streams to create islands or loops. This is because self-avoiding can get more extensive growth area and space. This is one of the reasons why the river branches occur mainly at the tip: The branch of a river also grows in the weakest part of the natural search for its division path. 


\subsection{Stickiness}

The stickiness characteristics of the river network system are mainly manifested in the diffusion-limited aggregation phenomenon embodied in the vein growth of the river branches. For example, river intrusion infiltration will strengthen its edges on the branch path. This allows the branch to continuously reinforce and develop branches at a higher level, thus constituting a larger branch group.

This is similar to the tips of a DLA cluster very rarely intersect other branches because new particles cannot reach them once they get too close to another branch. This can be interpreted as: If a single particle of free motion hits another particle, it gets stuck, becomes a cluster and continues to move; and when the new free particle hits a part of the existing structure, it gets stuck. This process can be repeated to obtain a large and evolving structural system.

The branching characteristics of river network fully reflect the growth mystery of natural world: The mechanism of fractal in nature is the path of survival after selection. If the system of the river network can be called a system that can grow continuously then if the characteristics of this structure are also given to buildings, can buildings also grow continuously topologically?

\section{Translation of the branch structure of river network}

To study the growth system of river network, the aim is to transform the growth principle of river network into an available organic ecological space. Using the geometry of nature, and more precisely, fractal geometry, this process is constructed to construct an achievable spatial construction of beauty based on complex geometric form systems.

Just as a river network is a large, growing system, if a growing epidermis is to be designed, it should also have the characteristics of these branches. In order to simulate the system of river network, this study takes the stable triangular structure as the initial element and grows into clusters iteratively.

First, the tension structure of an equilateral triangle is used as the atom of the structure [11]. Select the triangle on the one hand because it has a solid structure and on the other because it has a tendency to split (three sharp angles). The initial element of a triangle is not confined to a single plane, and when three planar triangles link their vertices separately, it forms a three-dimensional triangular cone. This is also the composition of the first set of iteration units (Fig. 2).

The connection points of each iteration unit are all sticky joints, and their development and linking directions are mutually avoided; a certain number of unit links form a stable cluster. Of course, this stable cluster can strengthen the edge of the original cluster, or it can be derived outward at a certain point, thus continuing to develop new clusters. This epidermal structure, symbolizing the river network, shows the characteristics of branches from unit to group and even the whole, which can be derived and expanded all the time. Like a river in full bloom, it became a system that could grow indefinitely. It is like being alive (Fig. 3). 


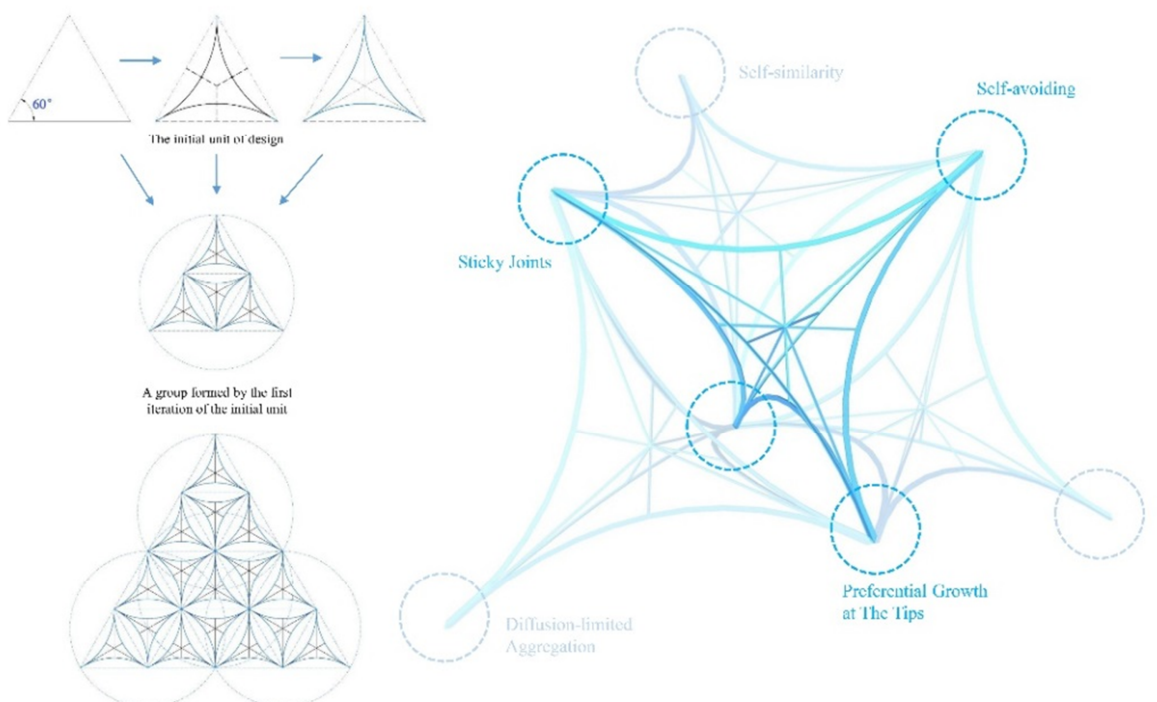

Fig. 2. Design evolution process

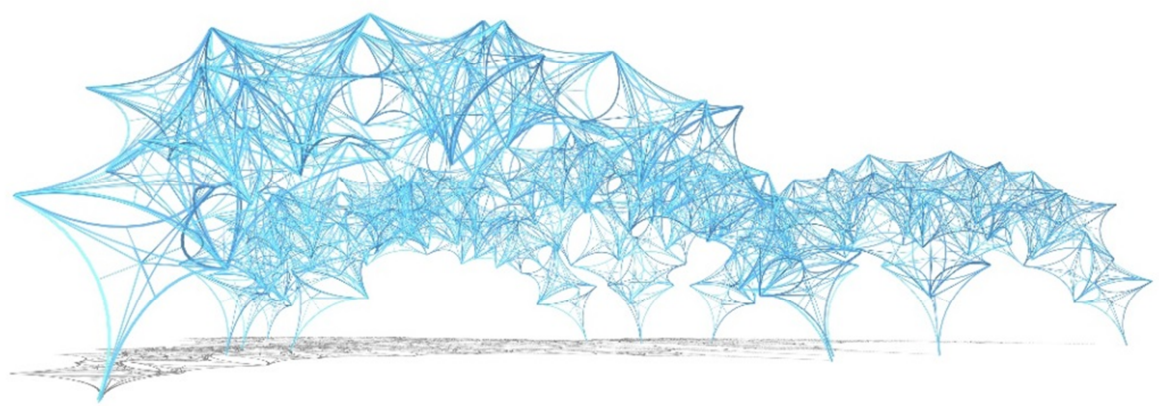

Fig. 3. Design and achievement

\section{A kind of bionic architecture}

\subsection{Bionic architecture}

There are numerous precedents for contemporary architecture to extract design forms from nature. People call it bionic architecture. Bionic architecture takes the function organization and image composition law of some organisms in the biological field as the research object. It explores the scientific and reasonable construction laws in nature, and through the application of these research results, enriches and improves the treatment methods of architecture, and promotes the efficient design and reasonable 
formation of architectural form, structure and functional layout. In a sense, bionic architecture is also a green building, and bionic technical means should also belong to the category of green technology.

The bionics of architecture is diverse, and the design mentioned in this paper is the bionics of architectural form. In addition to this, it includes urban environment bionics, using functional bionics and organizational structure bionics. Of course, sometimes there are also comprehensive bionic applications, forming a bionic whole of the city and architecture. The bionic of architectural form is the most common, it can not only achieve novel modeling, but also often can create extraordinary effect for the role of the new structure system. The earliest modern architect to use bionics was Antonio Gaudi, a Spaniard who designed apartment buildings in Barcelona in the form of distinct animal bones, a metaphor for the ancient legend of the coastal city's victory over the Dragons (Fig. 4).

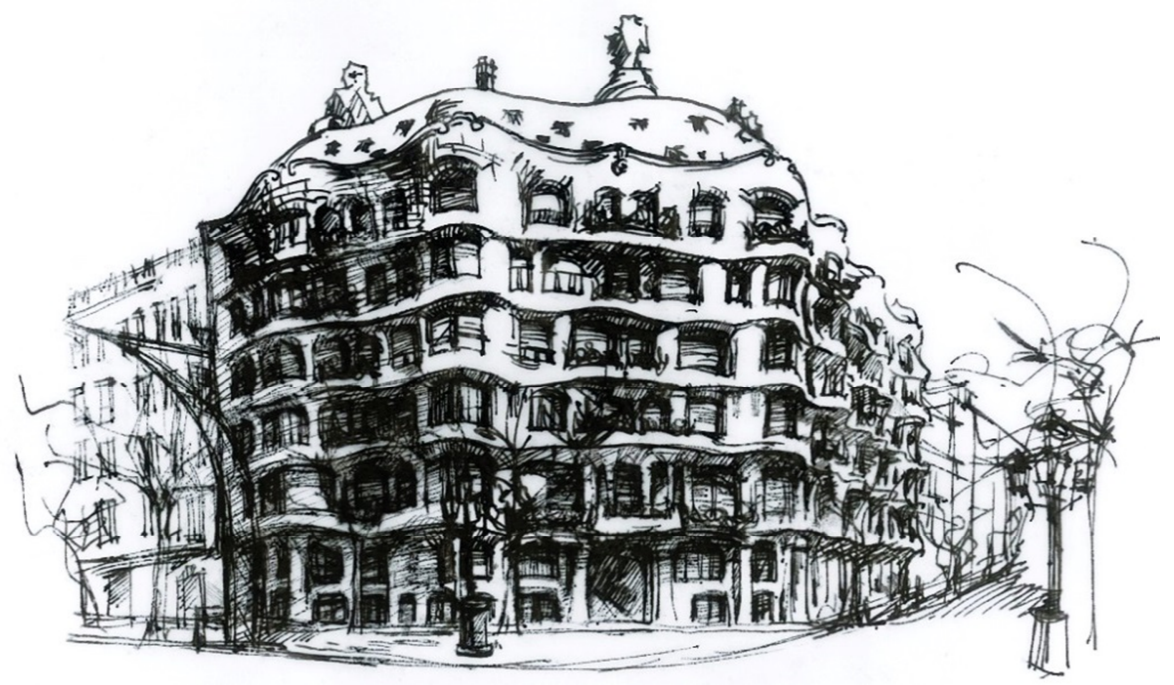

Fig. 4. CASA MILà is the most representative design of Spanish architect Antonio Gaudi. Many of Antonio Gaudi's architectural works have a bionic form

Designed and built by Frank Lloyd Wright in 1944, the Jacobs Villa in Wisconsin designed the house to resemble a ground mushroom. The Wisconsin State Johnson Wax Company headquarters, which he designed and built in 1950, is characterized by an imitation of a tree structure (Fig. 5). The Trans World Airlines, designed by Eero Saarinen in 1961 at John F. Kennedy International Airport in New York, is also a case attracting worldwide attention (Fig. 6). In 1964 Kenz Caltange designed the National Olympic Gymnasium in Tokyo, which uses suspension rope structure to imitate the shape of shell to achieve the organic combination of function, structure and shape, which is refreshing (Fig. 7). 


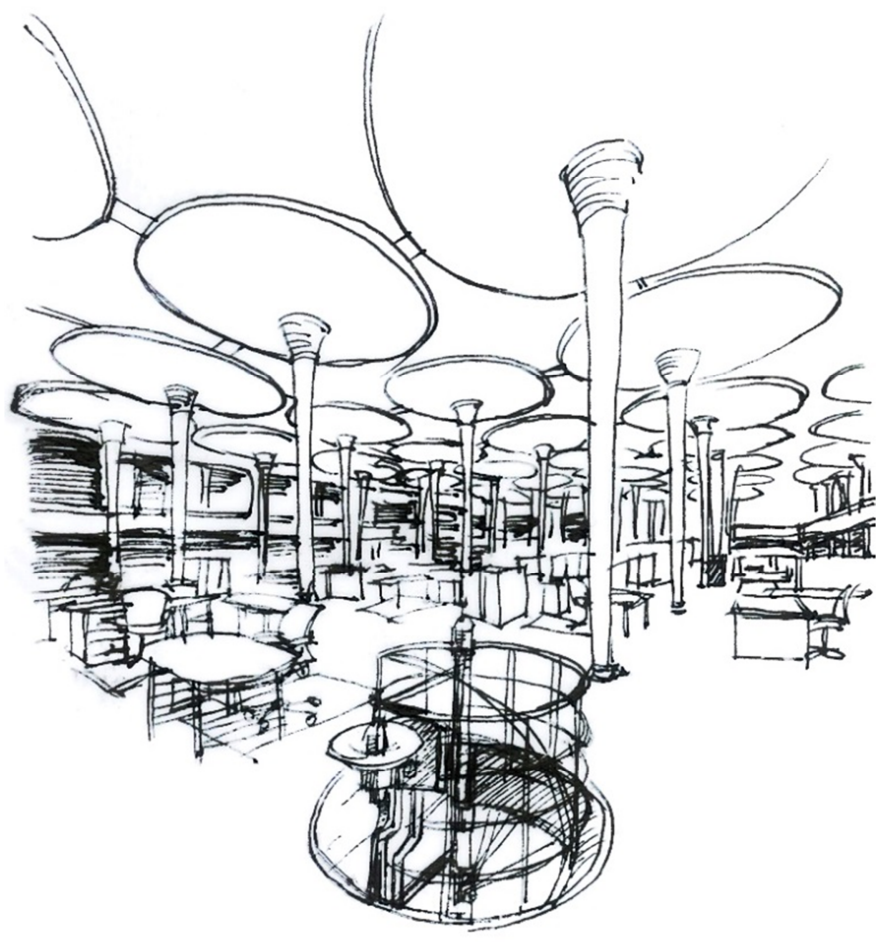

Fig. 5. Johnson Wax Company headquarters in America is most praised for its unique structural system. At the heart of this structural system is a kind of 'Dendriform' created by Wright. The bizarre column was inspired by Wright's study of the hollow structure of an Arizona cactus. It consists of four parts, each with a living name: crow's foot, stem, calyx, and petal.

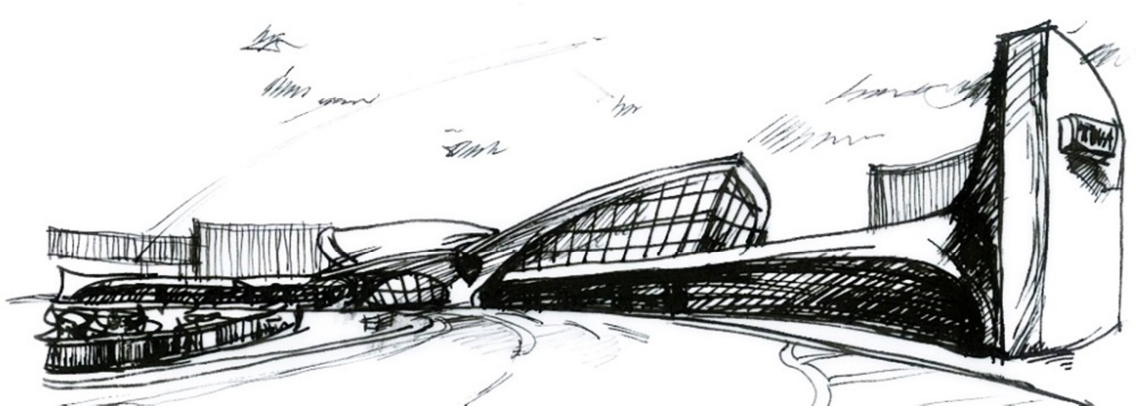

Fig. 6. John F. Kennedy International Airport in New York, designed by Eero Saarinen, 1961 


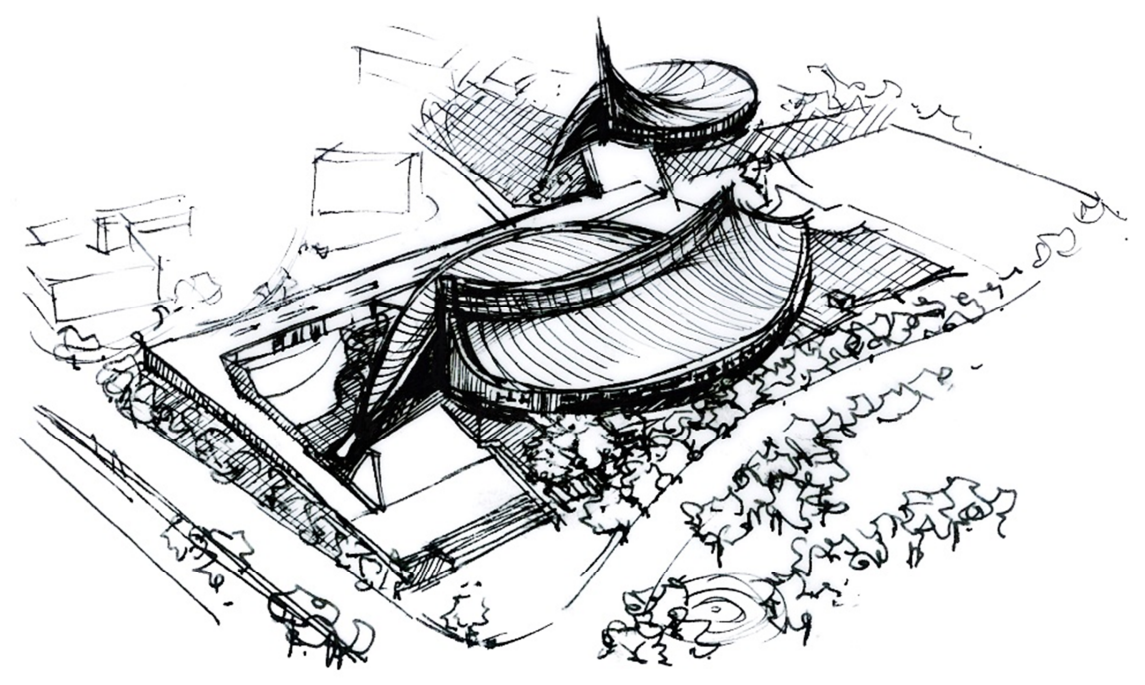

Fig. 7. The National Olympic Gymnasium in Tokyo, Designed by Kenz Caltange, 1964

\subsection{The significance of bionic architecture}

Architectural bionics has become a new trend of The Times and a new subject of architectural culture. Architectural bionics is an important means to inspire rational innovation of architecture and to achieve ecological balance and sustainable development of urban environment. Architectural bionics is a science based on the laws of natural ecology and social ecology combined with the characteristics of architectural science and technology. From nests and caves in ancient times to the appearance of all kinds of buildings today, all left traces of imitating nature.

From nests and caves in ancient times to the appearance of all kinds of buildings today, all left traces of imitating nature. However, with the rapid development of industrialization, human civilization has been alienated, which in turn destroys its own living environment. The most obvious in cities and buildings is the destruction of traditional buildings, for example in terms of heritage energy [12]. This aspect is not in line with the sustainable development of cities and buildings; on the other hand, it also makes architectural creation trapped in rigid machine products, constraining creativity. This is the reason why humans have begun to pay attention to bionics in recent decades. Nature is the best teacher of human beings, people all the time from the nature of inspiration and beneficial creation. Architectural bionics is not a simple imitation and copying. It is a creative method to absorb the growth texture of animals and plants and all the laws of natural ecology and adapt to the new environment by combining the characteristics of buildings. It is undoubtedly the most vital and a guarantee of sustainable development. 


\section{Conclusion}

The form of architecture should be: the principle of combining internal structure with external contour. The so-called natural architecture and lively architecture should be that its construction itself is architecture. The surface structure that can be grown, whether from the internal structure or the external contour, presents the division of the long-born cells, which is a high unity of architectural form and architectural spirit. A branching network is a representation of every level of living matter from a single cell to an ecosystem. Finding the growth and composing law of figurative space according to the natural phenomena in the macroscopic world. It is not only the spatial experience that emphasizes the unity of form and spirit, but also the structural transformation that brings theory into practice.

\section{Acknowledgements}

The Author would like to thank her doctoral supervisor, Dr. Gabriella Medvegy, Dean of the Faculty of Engineering and Information Technology, University of Pécs for her help in the research. The Author would also like to thank Prof. Yufang Zhou and Lecturer Wendong Wang from the School of Architecture, China Central Academy of Fine Arts, who gave guidance and help during the research.

\section{Open Access statement}

This is an open-access article distributed under the terms of the Creative Commons Attribution 4.0 International License (https://creativecommons.org/licenses/by/4.0/), which permits unrestricted use, distribution, and reproduction in any medium, provided the original author and source are credited, a link to the CC License is provided, and changes - if any - are indicated. (SID_1)

\section{References}

[1] Medvegy G., Veres G.Architecture and its afterlife; Green urbanity, Conference Proceedings on Places and Technologies 2015, Keeping up with Technologies to Make Healthy Places, Ljubljana, Slovenia, 2015, pp. 347-352.

[2] Ball P. Branches: Nature's Patterns: A tapestry in three parts, Oxford University Press, 2009.

[3] Tang Z., Feng J., Xu X., Shi Y. Research on the modeling and indexing method for river network, Journal of University of Electronic Science and Technology of China, Vol. 44, No. 4, 2015, pp. 611-616.

[4] Howard A. D. Drainage analysis in geological interpretation: A summation, Bulletin of the Amer. Assoc. Petroleum Geologists, Vol. 51, No. 11, 1967, pp. 2246-2259.

[5] Horton R. E. Erosional development of streams and their drainage basins; hydrophysical approach to quantitative morphology, Bulletin of the Geological Society of America, 1945, Vol. 56, 1957, pp. 275-370. 
[6] Strahler A. N. Quantitative analysis of watershed geomorphology, Trans. on American Geophysical Union, Vol. 38, No. 6, 1957, pp. 913-920.

[7] Liu H., Wang Z. Morphological feature and distribution of typical river networks, Journal of Hydraulic Engineering, Vol. 38, No. 11, 2007, pp. 1354-1357.

[8] Zhang L., Dai B. X., Wang G. Q., Li T. J., Wang H. The quantization of river network morphology based on the Tokunaga network, Science China Series D: Earth Science, Vol. 39, No. 10, 2009, pp. 1724-1731.

[9] Smart J. S. The analysis of drainage network composition, Earth Surface Processes and Landforms, Vol. 3, No. 2, 1978, pp. 129-170.

[10] Elhadad S., Baranyai B., Gyergyak J. The impact of building orientation on energy performance: A case study in New Minia, Egypt, Pollack Periodica, Vol. 13, No. 3, 2018, pp. 31-40.

[11] Qu G. D., Su D. Y., Lou Z. H. A new algorithm to automatically extract the drainage networks and catchments based on triangulation irregular network digital elevation model, Journal of Shanghai Jiaotong University (Science), Vol. 19, No. 3, 2014, pp. 367-377.

[12] Radha C. H. Traditional houses energy optimization using passive strategies, Pollack Periodica, Vol. 13, No. 2, 2018, pp. 185-194. 